\title{
Energy market and reserve market modeling in simultaneous and serial implementation methods with the aim of reducing electricity costs
}

\section{Ramin Ghoraba* and Mohammad Taghi Ameli}

${ }^{a}$ Department of Electrical Engineering, Power and Water University of Technology, Tehran, Iran

\begin{tabular}{|c|c|}
\hline $\bar{A}$ AR T I C L E I NFO & A B S T RACT \\
\hline $\begin{array}{l}\text { Article history: } \\
\text { Received 1 August } 2011 \\
\text { Available online } \\
10 \text { August } 2011 \\
\text { Keywords: } \\
\text { Ancillary service } \\
\text { Linear programming } \\
\text { Power market } \\
\text { Reserve market } \\
\text { Uniform pricing }\end{array}$ & $\begin{array}{l}\text { In competitive electricity markets, power needed for the network's reserve is } \\
\text { purchased from the ancillary service market. In this market, producing units and } \\
\text { buyers alike announce their offers. As will be seen, energy market and reserve market } \\
\text { implementation is possible with simultaneous method and serial method by choosing } \\
\text { each of the methods based on the type of market and other conditions. In this paper, } \\
\text { the energy market and the active power reserve market are simulated in two } \\
\text { formations as serial and simultaneous for a uniform pricing system. In each method, } \\
\text { limitations of transferring power over the lines, based on available transfer capacity } \\
\text { (ATC), is considered alongside the other constraints in the energy market and the } \\
\text { active power reserve market. Then, during network overload, economic dispatch is } \\
\text { accomplished between winner units in the reserve market by using a linear } \\
\text { optimization problem, and needed power is provided from these units at a minimal } \\
\text { cost. Finally, our proposed methods are implemented on an IEEE 39-bus test system } \\
\text { and results are analyzed. }\end{array}$ \\
\hline
\end{tabular}

\section{Introduction}

Operation in power systems has several branches, which has attracted many researchers. Moreover, restructuring and privatization in the electricity industry and commissioning of electricity markets in many countries has changed studies on power-system operations. In traditional systems, the operating of electricity networks is done by an integrated entity, which is often governmentally structured. In this system, supplying the needed reserve for the electricity networks is not overly complicated. But with restructuring in the electric industry, there have been some difficulties. In such a restructured system, the manufacturing part will participate in the market, as an independent identity, and thus cannot be a pre-determined portion of each of the participating units for providing reserve. To resolve this problem, the market has been launched as an active power reserve market. In this market, generators announce their offers to the market that include the steps of price and MW.

Next, by implementation of the market, a portion of each participating generator in the market is determined. In this perspective, confrontation between the energy and active power reserve markets

* Corresponding author Tel.: +989127755979

E-mail: eng.electronic@gmail.com (R. Ghoraba) 
provides a variety of issues. Different strategies are presented in different references for optimal performance in the reserve market alongside energy market. Madrigal and Quintana (2000) presented a model and solution approach to a daily energy and spinning-reserve electricity market clearing system. Allen and Ilic (2000) defined a price-based decision-making process for participating in a reserve market for power systems reliability. Gan and Litvinov (2002) have investigated the basic energy and reserve dispatch optimization (co-optimization) in the setting of a pool-based market. Jing Wang and Galiana (2003) offered a market model that includes demand-side reserve offers and where energy and reserve are jointly dispatched. Papadogiannis and Hatziargyriou (2004) presented an optimization algorithm, which provides for generation of economic dispatch, simultaneously minimizing the cost of primary reserve services while ensuring the secure operation of the power system in the presence of disturbances.

Bouffard and Galiana (2004) addressed the problem of reliability-constrained market clearing in pool-based electricity markets with unit commitment. Arroyo and Galiana (2005) analyzed some unresolved pricing issues in security-constrained electricity markets subject to transmission flow limits. Tongxin Zheng Litvinov (2006) discussed an alternative to the ex post pricing model currently under development within ISO New England's (ISO NE) ancillary service market. Wong and Fuller (2007) presented a stochastic linear programming model that can be used for pricing in electrical energy and reserve markets. It addresses capacity, energy and reserve dispatch problems that may arise from n-1 contingency scenarios. Haghighat et al. (2007) concentrated on the strategic interaction among suppliers in a centralized market, where electrical energy and spinning reserve are simultaneously traded. A bi-level optimization technique and a mathematical program with equilibrium constraints approach are utilized to develop an optimal bidding strategy for competitive suppliers participating in these markets.

Yamin et al. (2007) presented a type of unit commitment based on the optimizing of the producing companies' profits. In this reference, the constraints related to the system-required reserve in the design issue was considered. Costa and Simoes Costa (2007) used a method based on the system's optimal power flow for providing the required energy and reserve for network. Just and Weber (2008) presented a method for reserve-market price ratings according to the available price. Stacke and Cuervo (2008) presented a pricing model considering the simultaneous interaction of pool, bilateral and reserve markets in a power system. The model is able to work under classical marginal pricing (MP) or under the ldquopay-as-bidrdquo (PAB) pricing. Rainer and Arce (2008) determined a pricing strategy in the Chilean reserve market by following the contrast between the reserve market and the energy market. Ehsani et al. (2009) used the methods that show simultaneous optimization of the energy market and the secondary reserve market.

In this study, only a simultaneous implementation method for the energy market and the active power reserve market was formulated and solved using GAMS software. Amjady and Keynia (2010) predicted the required reserve in a competitive electricity market. In this study, a predictive reserverequirements engine was designed by combining artificial neural networks and a real genetic algorithm. A Levenberg-Marquadt (LM) algorithm was used for training. Nasr Azadani et al. (2010) used a Constraint Particle Swarm Optimization (CPSO) algorithm for optimal dispatch between the generators in the energy market and the reserve market. In this paper, serial implementation and simultaneous implementation of the energy market and the reserve market are formulated and compared. Simulation was performed with MATLAB software. Our study is organized as follows.

In the first section, a simultaneous implementation method is described and formulated. In section 2, a serial implementation method is described and formulated. Section 3 demonstrates the simulation method for contingency in the network. In section 4 is given a case study. Section 5 indicates the results and comparisons; and, in section 6, conclusions are expressed. 


\section{Design Issue}

In the energy market, generators and loads announce their offers and their bids to the market that include the steps of price and power. But, in the reserve market, only generators announce their offers to the market. The energy and reserve markets may run in serial method or in simultaneous method, each of which presents unique problems.

\subsection{Simultaneous Implementation Method}

In this method, the energy market and the reserve market are performed simultaneously. A mathematical definition of the problem should involve all constraints concerned with the energy market, the reserve market and the network. All of the implied simultaneous constraints for this section are mentioned below:

- Limitation of power produced by generators:

By following this constraint, generators producing power should be in the allowed range.

Based on the aforementioned constraints, the winning reserve by a generator on the market should be producible. This constraint is defined as follows:

$P G_{i}^{\min } \leq P G_{i}+P R_{i} \leq P G_{i}^{\max }$

where:

$P G_{i}^{\text {min }}$ : is the minimum power that can be produced by the $i^{\text {th }}$ generator

$P G_{i}^{\text {max }}$ : is the maximum power that can be produced by the $i^{t h}$ generator

$P G_{i}$ : is the total power won by the $i^{\text {th }}$ generator in the energy market and is calculated as follows:

$P G_{i}=\sum_{k} p g_{i, k}$

where:

$p g_{i, k}$ : is power won by the $i^{\text {th }}$ generator in the energy market related to the $k^{\text {th }}$ proposed step

$P R_{i}$ : is total power won by the $i^{t h}$ generator in the energy market and is calculated as follows:

$P R_{i}=\sum_{k} p r_{i, k}$

where:

$p r_{i, k}$ : is power won by the $i^{\text {th }}$ generator in the reserve market related to the $k^{\text {th }}$ proposed step

- Loads suggested steps limitation:

Power won by each load must be situated in the range of the suggested steps. This constraint is given as:

$0 \leq p l_{i, k} \leq p l_{i, k}^{\max }$

where:

$p l_{i, k}$ : is power won by the $i^{\text {th }}$ load in the energy market related to the $k^{\text {th }}$ proposed step

$p l_{i, k}^{\max }$ : is the power in the $i^{\text {th }}$ load in the energy market related to the $k^{\text {th }}$ proposed step 
- Limitation of suggested steps for a generator:

$0 \leq p g_{i, k} \leq p g_{i, k}^{\max }$

where:

$p g_{i, k}^{\max }$ : is the power in the $i^{t h}$ generator in the energy market related to the $k^{\text {th }}$ proposed step

- Limitation of steps for the reserve:

$0 \leq p r_{i, k} \leq p r_{i, k}^{\max }$

where:

$p r_{i, k}^{\max }$ : is the power in the $i^{\text {th }}$ load in the reserve market related to the $k^{\text {th }}$ proposed step

- Limitation of transferring power through the lines:

During the implementation of the market, limitation of transferring power through the lines should be considered. Otherwise, the result may cause the market to reject the network constraints. In considering the limitation of transferring power through the lines, the following equation is used:

$\left|f_{i j}+\Delta f_{i j} \leq f_{i j}^{\max }\right|$

where:

$f_{i j}$ : is transferring power from the line between bus $i$ and bus $j$

$\Delta f_{i j}$ : is the power variation in network lines, while all of the network loads increase rarely as required reserve

$f_{i j}$ and $\Delta f_{i j}$ are obtained from the DC power flow.

- Constraints related to DC power flow:

$f_{i j}=\frac{1}{X i j}\left(\theta_{i}-\theta_{j}\right)$

$P G_{i}-P L_{i}=\sum_{j} \frac{1}{X i j}\left(\theta_{i}-\theta_{j}\right)$

- Objective function:

In this issue, the main purpose of the energy market is to increase the social welfare. In addition, the main purpose of the reserve market is to reduce the reserve cost. According to these points, an objective function is defined as follows:

$$
o b j=\max \left\{\left[\sum_{j} \sum_{k} c l_{j k} \cdot p l_{j k}-\sum_{i} \sum_{k} c g_{i k} \cdot p g_{i k}\right]-\left[\sum_{i} \sum_{k}\left(c r_{i k} \cdot p r_{i k}+c o_{k} \cdot R f_{i}\right]\right\}\right.
$$

where:

$i$ : is introduced generator

$j$ : is introduced load

$k:$ is introduced proposed step

$R f_{i}$ : is a binary parameter. If it is 1 , the $i^{\text {th }}$ generator has won in the reserve market and if it is 0 , the $i^{\text {th }}$ generator has not won in the reserve market.

$c l$ : is the load's suggested price in the energy market

$c g$ : is the generator's suggested price in the energy market 
$\mathrm{cr}:$ is the generator's suggested price in the reserve market

$c o$ : is the availability price

Both of the relationships expressed above show the simultaneous implementation of the energy market and the reserve market in the form of an optimization problem.

\subsection{Serial Implementation Method}

In this case, the energy market is run first, followed by the reserve market. The constraints considered in this section are very similar to those for the simultaneous method.

\subsubsection{Implementation of the Energy Market}

Constraints considered are as follows:

- Limitation of power that is produced by generators:

By following this constraint, generators producing power should be in an allowed range.

Based on the aforementioned constraints, the winning reserve by a generator on the market should be producible. This constraint is defined as follows:

$P G_{i}^{\min } \leq P G_{i} \leq P G_{i}^{\max }$

- Limitation of suggested steps for the loads:

$0 \leq p l_{i, k} \leq p l_{i, k}^{\max }$

- Limitation of suggested steps for the generators:

$0 \leq p g_{i, k} \leq p g_{i, k}^{\max }$

- Limitation of transferring power through the lines:

$\left|f_{i j} \leq f_{i j}^{\max }\right|$

- Constraints concerned with DC power flow:

$f_{i j}=\frac{1}{X i j}\left(\theta_{i}-\theta_{j}\right)$

$P G_{i}-P L_{i}=\sum_{j} \frac{1}{X i j}\left(\theta_{i}-\theta_{j}\right)$

- Objective function:

In this issue, the main purpose of the energy market is to increase the social welfare and is defined as:

$o b j=\max \left\{\sum_{j} \sum_{k} c l_{j k} \cdot p l_{j k}-\sum_{i} \sum_{k} c g_{i k} \cdot p g_{i k}\right\}$

The relationship expressed above indicates the implementation of the energy market in the form of an optimization problem.

\subsubsection{Implementation of the Reserve Market}

The reserve market is implemented after the energy market. This subject has lead to a slight change in the reserve-market constraints. Constraints related to this section are as follows:

- Limitation of suggested steps for generators:

$0 \leq p r_{i, k} \leq p r_{i, k}^{\max }$

- Providing the required reserve constraint: 
$\sum_{k}^{30} p r_{i, k}=R e s$

- Limitation of transferring power through the lines:

In implementation of the reserve market, the remaining capacity of the lines should be put into the issue's simulation in the form of constraints. If the purchased reserve is used, overload should not occur in the network lines. This constraint can be considered as follows:

$\left|\Delta f_{i j}\right| \leq A T C_{i j}$

In this formula, $A T C$ is the available transfer capacity and defined as:

$A T C_{i j}=f_{i j}^{\max }-f_{i j}-f m_{i j}$

In this formula, $f m_{i j}$ is the security margin of the lines and is placed as an issue in order to maintain line security and prevent reaching the line capacity.

- Limitation of reserve can be produced by the generators:

$\max \left\{0, P G_{i}^{\min }-P G_{i}\right\} \leq P r_{i} \leq P G_{i}^{\max }-P G_{i}$

This constraint forces power won by each generator in the reserve market to be in the range of the remaining capacity of the system.

- Objective function:

The main purpose of the objective function in this section is to reduce the reserve cost and is defined as follows:

$o b j=\min \left\{\sum_{i} \sum_{k}\left(c r_{i k} \cdot p r_{i k}+c o_{k} \cdot R f_{i}\right\}\right.$

\section{Contingency Simulation in the Network}

After implementation of the energy market and the reserve market, and in case of sudden increases of load or a sudden decrease in production in the network, network operations will be done from the winning units in the reserve market, and lack of desired production is provided with the lowest cost. In this paper, this contingency has been applied as a sudden increase in load. In this regard, some of the constraints must be respected. This problem is defined in the form of an optimization problem that is bound to the network security constraints and participating units in the market. Different parts of this optimization problem are as follows:

- Limitation of power production in generators

- Supply shortage in load constraint

- Limitation of transferring power through the lines

- Limitation on the use of purchased reserve

Fig. 1 shows the flowchart for the serial method in the energy market and reserve market implementations considering contingencies. Fig. 2 shows the flowchart for the simultaneous method in the energy market and reserve market implementations considering contingencies.

\section{Case Study}

The IEEE 39-bus test system was used for this case study. Tables 1 and 2 show the information about the proposed energy market and the reserve market for generators and loads. 


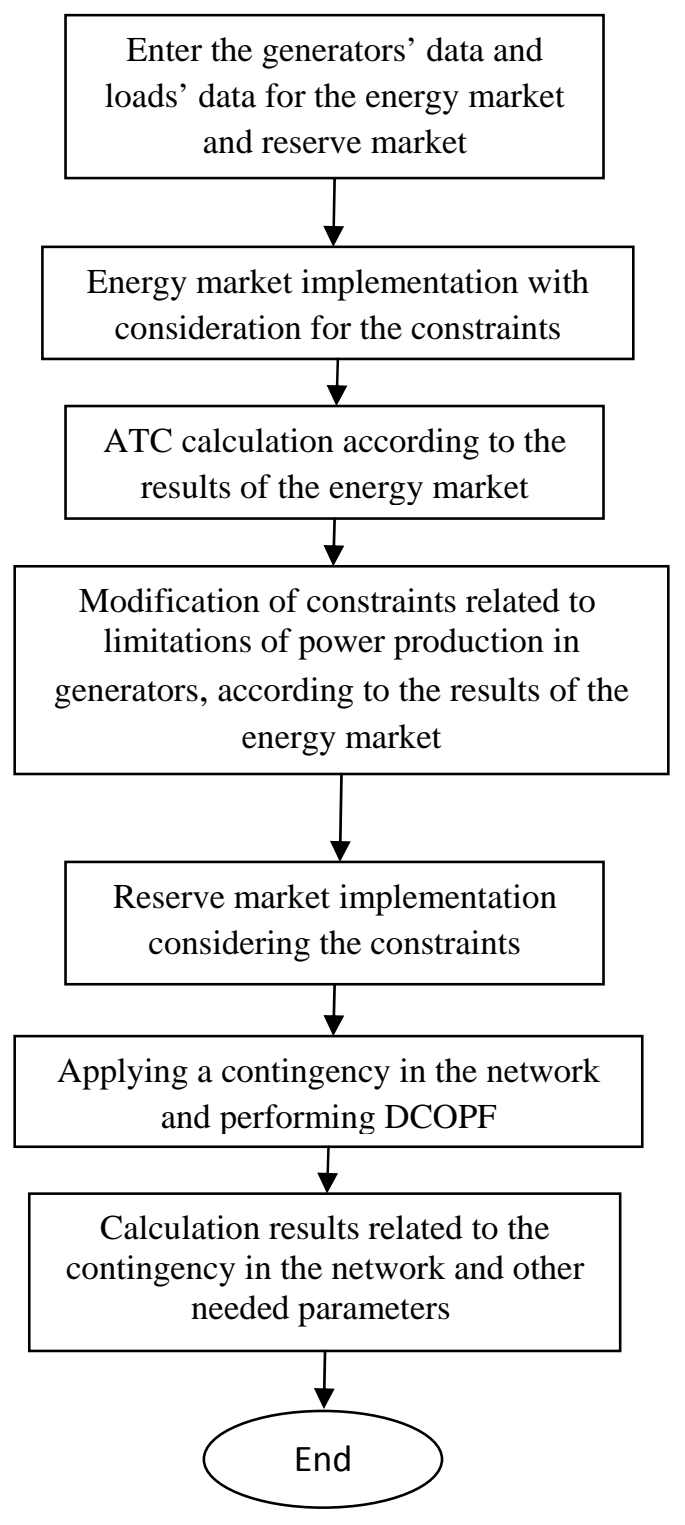

Fig. 1. Flowchart for the serial method

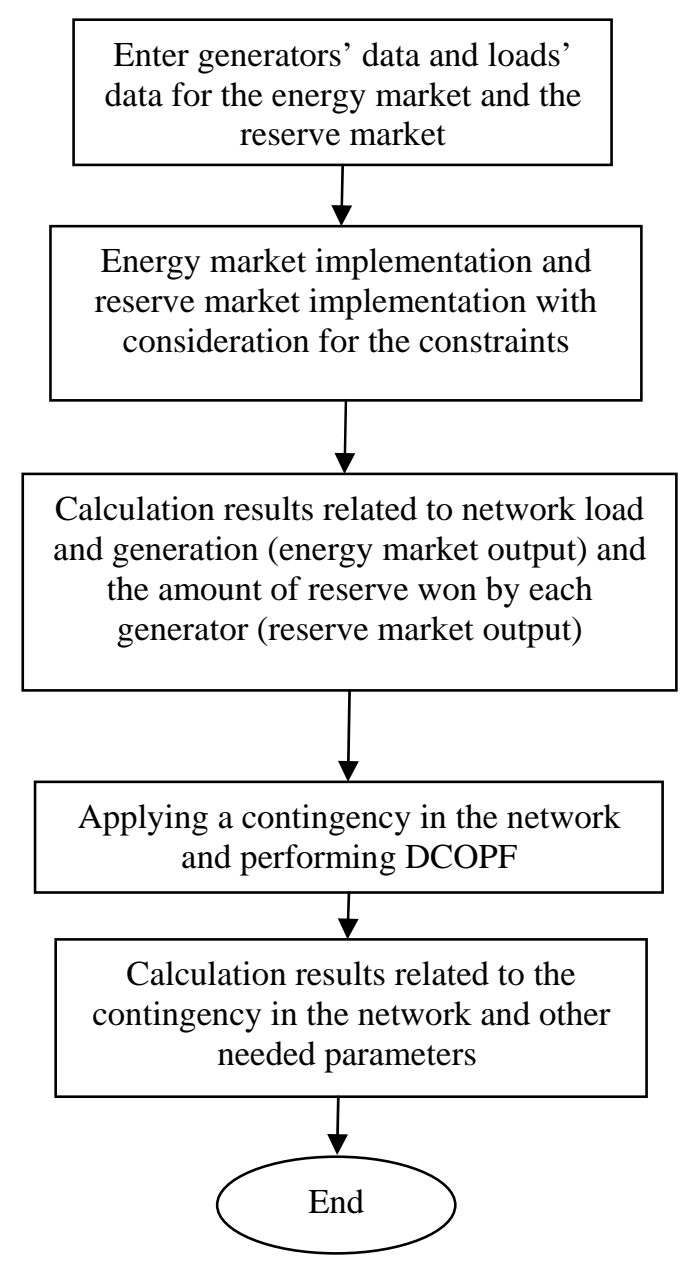

Fig. 2. Flowchart for the simultaneous method

In Tables 1 and 2, the first row shows the information about the power suggested steps and the second row shows the price of each step.

\section{Comparison of results}

Simulation results show that the energy market clearing price in the energy market in the serial method is less than the energy market clearing price in the simultaneous method. Also, the total power exchanged in the energy market versus the serial method is more than the total power exchanged in the simultaneous method. This issue shows that the serial method has better performance in the energy market when compared with the simultaneous method. On the other hand, the reserve market clearing price in the simultaneous method and the required cost for supplying the load increase in the network are less than the serial method. This shows that the serial implementation of the reserve market has better performance than the simultaneous implementation. The reason for this is that in the serial implementation of the reserve market, what the reserve market has to offer cannot be seen. This causes generators with low energy-market prices to come to their maximum production capacity and, if their reserve market price is appropriate, they do not have the ability to produce. Therefore, units that are more expensive remain in the reserve market. But in the 
simultaneous method, the reserve market prices are seen in the energy market. Therefore, cheaper generators are selected for the reserve market. This also causes the reserve market price to come down. Finally, we can say that the serial method is better for networks that have good reliability and often have minimal load variations. The simultaneous method will have a better efficiency at reducing costs in the networks that have loads with unpredictable severe changes and constantly need to use the purchased reserve. Figure 4 shows the graphs related to the market clearing in both methods. As can be seen, in both cases the market has cleared at a point other than the point of intersection of supply and demand curve. This is because of a power limitation in network lines. Market clearing at the point of intersection of the two curves is causing the overload on some lines. This has caused the market to be cleared at a point other than the point of intersection of the two curves. To fix this problem, there should be an increase in the capacity of the critical lines.
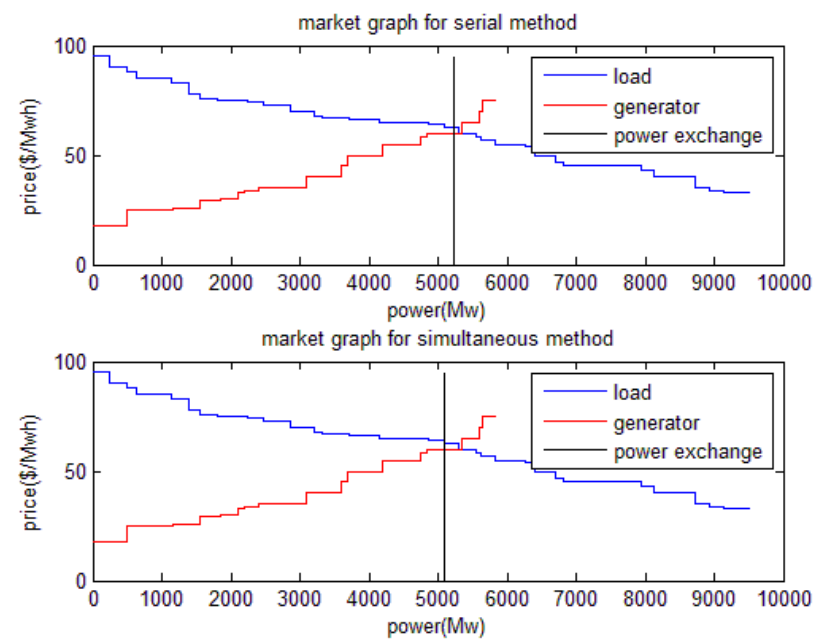

Fig. 4. Market graph for serial and simultaneous methods

Table 1

Generators Information

\begin{tabular}{|c|c|c|c|c|c|c|c|c|c|}
\hline \multirow[b]{2}{*}{ Bus number } & \multicolumn{4}{|c|}{ Energy Market } & \multicolumn{5}{|l|}{ Reserve Market } \\
\hline & Step No: & $\begin{array}{l}\text { Step } \\
\text { one }\end{array}$ & $\begin{array}{l}\text { Step } \\
\text { two }\end{array}$ & $\begin{array}{l}\text { Step } \\
\text { three }\end{array}$ & Availability Price (\$) & Step No: & $\begin{array}{l}\text { Step } \\
\text { one }\end{array}$ & $\begin{array}{l}\text { Step } \\
\text { two }\end{array}$ & $\begin{array}{l}\text { Step } \\
\text { three }\end{array}$ \\
\hline & $(\mathrm{MW})$ & 100 & 100 & 50 & \multirow{3}{*}{100} & $(\mathrm{MW})$ & 20 & 20 & 20 \\
\hline \multirow[t]{2}{*}{30} & (\$/Mwh) & 33 & 45 & 60 & & (\$/Mwh) & 10 & 12 & 15 \\
\hline & (MW) & 100 & 50 & 50 & & $(\mathrm{MW})$ & 20 & 20 & 20 \\
\hline \multirow[t]{2}{*}{31} & (\$/Mwh) & 55 & 65 & 75 & \multirow[t]{2}{*}{100} & (\$/Mwh) & 13 & 14.5 & 17 \\
\hline & (MW) & 300 & 300 & 100 & & (MW) & 60 & 60 & 50 \\
\hline \multirow[t]{2}{*}{32} & (\$/Mwh) & 29 & 40 & 65 & \multirow[t]{2}{*}{100} & (\$/Mwh) & 13 & 14 & 16 \\
\hline & (MW) & 400 & 200 & 200 & & (MW) & 50 & 50 & 50 \\
\hline \multirow[t]{2}{*}{33} & (\$/Mwh) & 26 & 34 & 55 & \multirow[t]{2}{*}{100} & (\$/Mwh) & 14 & 16 & 17 \\
\hline & (MW) & 100 & 50 & 50 & & (MW) & 50 & 50 & 50 \\
\hline \multirow[t]{2}{*}{34} & (\$/Mwh) & 50 & 60 & 70 & \multirow[t]{2}{*}{100} & (\$/Mwh) & 10 & 12 & 14 \\
\hline & (MW) & 200 & 200 & 150 & & (MW) & 100 & 100 & 60 \\
\hline \multirow[t]{2}{*}{35} & (\$/Mwh) & 35 & 40 & 75 & \multirow[t]{2}{*}{100} & (\$/Mwh) & 14 & 16.5 & 18 \\
\hline & (MW) & 250 & 250 & 250 & & (MW) & 50 & 50 & 50 \\
\hline \multirow[t]{2}{*}{36} & (\$/Mwh) & 30 & 35 & 55 & \multirow[t]{2}{*}{100} & (\$/Mwh) & 13 & 14 & 16.5 \\
\hline & (MW) & 250 & 150 & 100 & & (MW) & 100 & 60 & 60 \\
\hline \multirow[t]{2}{*}{37} & (\$/Mwh) & 25 & 35 & 58 & \multirow[t]{2}{*}{100} & (\$/Mwh) & 12 & 14 & 15.5 \\
\hline & (MW) & 400 & 400 & 100 & & (MW) & 100 & 100 & 50 \\
\hline \multirow[t]{2}{*}{38} & (\$/Mwh) & 50 & 60 & 65 & \multirow[t]{2}{*}{100} & (\$/Mwh) & 14 & 14.5 & 16 \\
\hline & (MW) & 500 & 400 & 100 & & (MW) & 80 & 50 & 50 \\
\hline 39 & (\$/Mwh) & 18 & 25 & 35 & 100 & (\$/Mwh) & 19 & 20 & 25 \\
\hline
\end{tabular}


Table 2

Loads Information

\begin{tabular}{|c|c|c|c|c|c|c|c|c|c|}
\hline $\begin{array}{l}\text { Bus } \\
\text { number }\end{array}$ & Step No: & $\begin{array}{l}\text { Step } \\
\text { one }\end{array}$ & $\begin{array}{l}\text { Step } \\
\text { two }\end{array}$ & $\begin{array}{l}\text { Step } \\
\text { three }\end{array}$ & $\begin{array}{l}\text { Bus } \\
\text { number }\end{array}$ & Step No: & $\begin{array}{l}\text { Step } \\
\text { one }\end{array}$ & $\begin{array}{l}\text { Step } \\
\text { two }\end{array}$ & $\begin{array}{l}\text { Step } \\
\text { three }\end{array}$ \\
\hline & $(\mathrm{MW})$ & 200 & 100 & 100 & \multirow{3}{*}{23} & $(\mathrm{MW})$ & 160 & 100 & 100 \\
\hline \multirow[t]{2}{*}{3} & (\$/Mwh) & 65 & 55 & 45 & & (\$/Mwh) & 78 & 66 & 50 \\
\hline & (MW) & 200 & 200 & 200 & & $(\mathrm{MW})$ & 135 & 100 & 80 \\
\hline \multirow[t]{2}{*}{4} & (\$/Mwh) & 73 & 67 & 40 & \multirow[t]{2}{*}{24} & (\$/Mwh) & 88 & 68 & 58 \\
\hline & (MW) & 250 & 200 & 200 & & $(\mathrm{MW})$ & 220 & 100 & 100 \\
\hline \multirow[t]{2}{*}{7} & (\$/Mwh) & 95 & 45 & 40 & \multirow[t]{2}{*}{25} & (\$/Mwh) & 74 & 65 & 45 \\
\hline & (MW) & 50 & 50 & 50 & & (MW) & 230 & 150 & 100 \\
\hline \multirow[t]{2}{*}{8} & (\$/Mwh) & 75 & 60 & 45 & \multirow[t]{2}{*}{26} & (\$/Mwh) & 64 & 54 & 34 \\
\hline & (MW) & 200 & 100 & 100 & & (MW) & 340 & 200 & 200 \\
\hline \multirow[t]{2}{*}{12} & (\$/Mwh) & 60 & 55 & 35 & \multirow[t]{2}{*}{27} & (\$/Mwh) & 66 & 43 & 33 \\
\hline & (MW) & 250 & 150 & 100 & & (MW) & 250 & 150 & 100 \\
\hline \multirow[t]{2}{*}{15} & (\$/Mwh) & 90 & 70 & 40 & \multirow[t]{2}{*}{28} & (\$/Mwh) & 76 & 55 & 35 \\
\hline & $(\mathrm{MW})$ & 200 & 200 & 200 & & (MW) & 200 & 200 & 100 \\
\hline \multirow[t]{2}{*}{16} & (\$/Mwh) & 70 & 63 & 33 & \multirow[t]{2}{*}{29} & (\$/Mwh) & 67 & 57 & 47 \\
\hline & (MW) & 150 & 150 & 100 & & $(\mathrm{MW})$ & 140 & 200 & 200 \\
\hline \multirow[t]{2}{*}{18} & (\$/Mwh) & 65 & 45 & 40 & \multirow[t]{2}{*}{30} & (\$/Mwh) & 65 & 50 & 45 \\
\hline & (MW) & 250 & 200 & 100 & & (MW) & 500 & 400 & 250 \\
\hline \multirow[t]{2}{*}{20} & (\$/Mwh) & 83 & 73 & 34 & \multirow[t]{3}{*}{31} & (\$/Mwh) & 85 & 75 & 45 \\
\hline & $(\mathrm{MW})$ & 120 & 80 & 80 & & & & & \\
\hline 21 & (\$/Mwh) & 65 & 55 & 45 & & & & & \\
\hline
\end{tabular}

Table 3 shows the required information for needed reserve and load increasing.

Table 3

Amount of Load Increasing

\begin{tabular}{ll}
\hline Bus number & The percent of load increasing \\
\hline 3 & $20 \%$ \\
4 & $20 \%$ \\
20 & $20 \%$ \\
24 & $20 \%$ \\
31 & $20 \%$ \\
39 & $20 \%$
\end{tabular}

Reserve $=15 \%$

Table 4 shows the results of serial implementation of the market and the simultaneous implementation of market.

Table 4

Serial Implementation and Simultaneous Implementation of Market

\begin{tabular}{lcc}
\hline & Serial method & Simultaneous method \\
\hline Energy cost (\$) & 329490 & 321692 \\
Reserve cost after Contingency (\$) & 8928 & 5229 \\
Total cost (\$) & 338418 & 326921 \\
Energy market clearing price (\$/Mwh) & 63 & 63.14 \\
Reserve market clearing price (\$/Mwh) & 31 & 18 \\
\hline
\end{tabular}

\section{Conclusion}

In this paper, the serial implementation method and the simultaneous implementation method are presented for the implementation of the energy market and the reserve market. The methods are 
defined in the form of optimization problems and are used in a case study on the IEEE 39-bus test system. Results from the case study show that the serial method has better performance in the energy market and the market price will be less. Also, the simultaneous method has better performance in the reserve market. Finally, the serial method is more suitable in networks that have a high reliability. And the simultaneous method has better performance in networks that have low reliability and purchased reserve should be used regularly.

\section{References}

Allen, E.H. \& Ilic, M.D. (2000). Reserve markets for power systems reliability. IEEE Transactions on Power Systems, 15(1), 228.

Amjady, N. \& Keynia, F. (2010). A new spinning reserve requirement forecast method for deregulated electricity markets. Applied Energy, 87(6), 1870-1879.

Arroyo, J.M. \& Galiana, F.D. (2005). Energy and reserve pricing in security and network-constrained electricity markets. IEEE Transactions on Power Systems, 20(2), 634

Costa, A.I., \& Simoes Costa, A. (2007). Energy and Ancillary Service Dispatch Through Dynamic Optimal Power Flow. Electric power systems research, 77(8), 1047-1055.

Ehsani Ranjbar, A.M. \& Fotuhi-Firuzabad, M. (2009). A proposed model for co-optimization of energy and reserve in competitive electricity markets. Applied Mathematical Modelling, 33(1), 92109.

Gan, D. \& Litvinov, E. (2002). Energy and Reserve Market Designs with Explicit Consideration to Lost Opportunity Costs. Power Engineering Review, IEEE, 22(12), 61-66.

Haghighat, H. Seifi, H. \& Kian, A.R. (2007). Gaming Analysis in Joint Energy and Spinning Reserve Markets. IEEE Transactions on Power Systems, 22(4), 2074-2085.

Just, S. \& Weber, C. (2008). Pricing of reserves: Valuing system reserve capacity against spot prices in electricity markets. Energy Economics, 30(6), 3198-3221.

Madrigal, M. \& Quintana, V.H. (2000). A security-constrained energy and spinning reserve markets clearing system using an interior-point method. IEEE Transactions on Power Systems, 15(4), 1410-1416.

Nasr Azadani, N. Hosseinian \& S.H. Moradzadeh, B. (2010). Generation and reserve dispatch in a competitive market using constrained particle swarm optimization. International Journal of Electrical Power \& Energy Systems, 32(1), 79-86.

Papadogiannis, K.A. \& Hatziargyriou, N.D. (2004). Optimal allocation of primary reserve services in energy markets. IEEE Transactions on Power Systems, 19(1), 652-659.

Rainer, R. \& Arce, A. (2008). Form A Bundled Energy Capacity Pricing Model To An Ancillary Service Pricing model. Energy Policy, 36(8), 2878-2886.

Redondo, J.W., \& N.E. Galiana, F.D. (2003). Demand-side reserve offers in joint energy/reserve electricity markets. IEEE Transactions on Power Systems,18(4), 1300-1306.

Stacke, F. \& Cuervo, P. (2008). A Combined Pool/Bilateral/Reserve Electricity Market Operating Under Pay-as-Bid Pricing. IEEE Transactions on Power Systems, 23(4), 1601-1610.

Tongxin Zheng Litvinov, E. (2006). Ex Post Pricing in the Co-Optimized Energy and Reserve Market. IEEE Transactions on Power Systems, 21(4), 1528-1538.

Wong, S. \& Fuller, J.D. (2007). Pricing Energy and Reserves Using Stochastic Optimization in an Alternative Electricity Market. IEEE Transactions on Power Systems, 22(2), 631-638.

Yamin, H.Y. El-Dwairi, Q. \& Shahidehpour, S.M. (2007). A new approach for GenCos profit based unit commitment in day-ahead competitive electricity markets considering reserve uncertainty. International Journal of Electrical Power \& Energy Systems, 29(8), 609-616. 